\title{
Türkiye'de Travma Sonrası Stres ve Büyüme Konusunda Gerçekleştirilmiş Olan Çalışmaların İncelenmesi
}

\author{
DOI: 10.26466/opus.960263
}

\author{
* \\ Esra Teke ${ }^{*}$ Selahattin Avşaroğlu** \\ * Dr. Öğr., Necmettin Erbakan Üniversitesi, Eğitim Fakültesi, Konya/Türkiye \\ E-Posta: esradogru1@gmail.com \\ ORCID: $\quad$ 0000-0002-8436-2169 \\ ** Prof. Dr., Necmettin Erbakan Üniversitesi, Eğitim Fakültesi, Konya/Türkiye \\ E-Posta: seloavsar@gmail.com \\ ORCID: $\quad$ 0000-0002-0953-2922
}

Öz

Bu araştırmanın amacl, Türkiye'de travma sonrası stres ve büyüme konusunda gerçekleştirilmiş olan çalışmaları sistematik bir şekilde incelemektir. Araştırmada, travma sonrası stres ve büyüme konusunda yayımlanmış olan lisansüstü tez ve araştırma makaleleri kapsamlı ve yapılandırılmış bir şekilde taranmıştır. Bu kapsamda çeşitli dâhil edilme ve hariç tutulma kriterleri göz önünde bulundurularak çalışmaların bulguları sentezlenmiştir. Araştırma sistematik derleme çalışmasıdır ve doküman analizi yöntemi ile gerçekleştirilmiştir. Araştırmanın çalışma grubunu belirlemek amacıyla 24 Mayıs-15 Haziran 2021 tarihleri arasında YÖKTEZ ve ULAKBIM veri tabanlarmda yapilan taramalarda 2012-2021 yılları arasında yayımlanmış 552 lisansüstü teze ve 290 makaleye ulaşılmıştır. Bunlar arasından dahil edilme kriterleri göz önünde bulundurularak 18 lisansüstü tez ve 6 makale araştırmanın çalışma grubunu oluşturmuştur. Çalışma grubu içerisinde yer alan tez ve makalelerin incelenmesinde araştırmacılar tarafindan hazırlanan "Araştırma Değerlendirme Formu" kullanılmıştır. Çalışmalar, araştırmanın yıll, araştırmanın türü, araştırma yöntemi, çalışma grubu, çalışma grubunun büyüklü̈̆̈̈̈, lisansüstü tezin türü ve yayımlandığı enstitü, araştırmada kullanılan değ̊işkenler ölçütleri çerçevesinde incelenmiştir. Araştırmanın sonuçları, alanyazın ışı̆̆ında tartışılmış ve önerilerde bulunulmuştur.

Anahtar Kelimeler: Travma, Travma Sonrası Stres, Travma Sonresı Büyüme. 


\title{
A Review of Studies on Post-Traumatic Stress and Growth Carried in Turkey
}

$*$

\begin{abstract}
The aim of this research is to examine systematically the studies on post-traumatic stress and growth in Turkey. In the research, postgraduate theses and research articles published on post-traumatic stress and growth were scanned in a comprehensive way. In this context, the findings of the studies were synthesized by considering various inclusion and exclusion criteria. The research is a systematic review study and was carried out by document analysis method. In order to determine the study group of the research, 552 graduate theses and 290 articles published between 2012 and 2021 were reached in the searches made in YÖKTEZ and ULAKBIM databases between 24 May and 15 June 2021. Considering the inclusion criteria, 18 postgraduate theses and 6 articles formed the study group of the research. The "Research Evaluation Form" prepared by the researchers was used in the examination of theses and articles in the study group. The studies were examined in terms of the year of the research, the type of the research, the research method, the study group, the size of the study group, the type of the postgraduate thesis and the institute where it was published, and the variables used in the research. The results of the research were discussed in the light of the literature and suggestions were made.
\end{abstract}

Key Words: Trauma, Post-Traumatic Stress, Post-Traumatic Growth. 


\section{Giriş}

Travma aniden gelişen, kontrol edilemeyen, olumsuz yaşam olayları şeklinde tanımlanmaktadır (Carlson ve Dalenberg, 2000; Hapke, Schumann, Rumpf, John ve Meyer, 2006). Bu olaylar bireyde korku, çaresizlik gibi duyguların meydana gelmesine neden olabilmekte ve bireylerin duygu, düşünce ve ruhsal durumlarını uzun süre etkisi altına alabilmektedir (Özen, 2017).

Bireyler travmatik olaylar sonrasında duygusal, bilişsel, bedensel ve davranışsal tepkiler verebilmektedir (Kanat ve Özpolat, 2016). Travmatik yaşam olaylarının hemen sonrasında bu belirtilerin ortaya çıkması normaldir (Kessler vd., 2005). Travmatik olaya maruz kalan bireylerin bu olayın üzerinden uzun zaman geçmesine rağmen bu belirtileri ilk günkü şiddetiyle yaşamaya devam etmesi (Davison ve Neale, 2004; Deblinger, Steer ve Lippmann 1999) ve bu durumun kronik bir hale gelmesi ise travma sonrası stres bozukluğu olarak ifade edilmektedir (Işıklı ve Keser, 2020).

Travma sonrası stres bozukluğu gösteren bireyler, hoş olmayan ve yinelenen bir şekilde travmatik olayı hatırlayabilmekte ve bu olayları hatırlarken psikolojik ve fizyolojik sıkıntılar yaşayabilmektedirler (RivasDiez, Sanchez-Lopez ve Rodrigo-Holgado, 2013; Sharhabani-Arzy, Amir, Kotler ve Liran 2003). Bilişsel, duygusal, davranışsal ve fizyolojik olarak kaçınma tepkileri verebilmektedirler (Rivas-Diez vd., 2013). Kendilerine ve diğerlerine yönelik yoğun öfke duygusu yaşayabilmekte (Dunmore, Clark ve Ehlers, 2001) ve mevcut durumlara yönelik olumsuz değerlendirmelerde bulunabilmektedirler (Ehlers ve Clark, 2000). Sürekli tehlike altındaymış gibi aşırı tepkiler gösterebilmektedirler (Brewin, 2011; Şuer, 2005).

Travmatik olaylar neticesinde bireyler geleceğe yönelik güvenlerini ve güvenlik duygularını kaybedebilmekte, tehditlere karşı verdikleri aşırı duygusal tepkiler sonucunda dengesizlik duygusu ve kontrol kaybı yaşayabilmektedirler (Bergner, 2009). Bununla birlikte travmatik bir yaşantının ardından bazı olumlu sonuçların ortaya çıkabileceğini düşündüren çalışmalar da vardır (İnci ve Boztepe, 2013). Literatürde bireylerin zorlu yaşam deneyimleriyle mücadeleleri sonucunda ortaya 
çıkan bu olumlu psikolojik değişim, travma sonrası büyüme olarak tanımlanmaktadır (Tedeschi ve Calhoun 2004).

Travma sonrası büyüme, travmatik olaylardan sonra insanlara daha derin bir bakış açısı ve güç sağlayabilmektedir. Bu bağlamda travma sonrası büyüme düzeyi yüksek olan bireyler, yaşamlarındaki sorunlarla baş edebilecek kadar güçlü hissedebilmekte ve travmanın olumlu sonuçlarına odaklanarak, iyileştirilmiş baş etme mekanizmalarına ve psikolojik iyiliğe sahip olabilmektedirler (Özçetin ve Hiçdurmaz, 2017).

Yapılan çalışmalarda travma sonrası büyüme ile iyimserlik, problem çözme becerisi (Karaman ve Tarım, 2018) affetme ve öz-anlayış arasında ilişkinin olduğu bulunmuştur (Gökmen ve Deniz, 2020). Tedeschi ve Calhoun (2004) da travma sonrası büyüme ile psikolojik sağlamlık, dayanıklılık, iyimserlik ve tutarlılık algısının ilişkili kavramlar olduğunu belirtmişlerdir.

Kavramsal açıklamalar neticesinde travma sonrası büyüme ve travma sonrası stres birbirine zıt olan kavramlar olarak değerlendirilmektedir. Oysa literatürde yer alan çalışmalar incelendiğinde bu iki değişken arasında pozitif yönde ilişkiye dair bulguların olduğunu gösteren çalışmalara rastlanmıştır (Solomon ve Dekel, 2007; Tekcan, 2018). Bununla birlikte literatürde bu iki değişken arasında negatif bir ilişkinin bulunduğuna (Frazier, Conlon ve Glaser, 2001) ya da herhangi bir anlamlı ilişkinin bulunmadığına dair bulgulara da rastlanmıştır (Salsman, Segerstrom, Brechting, Carlson ve Andrykowski, 2009). Dolayısıyla yapılan bu çalışmanın araştırmalarda yer alan bu çelişkilerin anlaşılması, araştırma sonuçlarının bütünleştirmesi açısından önemli olduğu düşünülmektedir.

Travma sonrası stres ve büyüme kavramları günümüzde özellikle deprem ve salgın gibi travmatik yaşam olayları ile birlikte sıklıkla karşımıza çıkar hale gelmiştir. Özellikle pozitif psikolojinin de gelişmesiyle birlikte travma sonrası büyüme kavramı daha çok anılır olmuştur. Bu durum, travmatik olaylar sonucunda neden bazı insanlar travma sonrası stres gösterirken bazı insanlar travma sonrası büyüme göstermektedir sorusunun sorulmasına da neden olmuştur. $\mathrm{Bu}$ bağlamda gerçekleştirilen çalışmada travma sonrası stres ve büyümeyi birlikte ele alan araştırmalar ve bu araştırmaların sonuçları incelenerek konuya bir çerçeve oluşturulması hedeflenmiştir. Ayrıca konuyla ilgili 
alanyazın taraması kapsamında ele alınan çalışmaların son 10 yılı kapsaması ve bu çalışmaların farklı değişkenlere göre incelenmesi, hem var olan durumun anlaşılmasını hem de ülkemizde yapılacak yeni çalışmalara ışık tutulmasını sağlayacaktır. Ek olarak literatürde travma sonrası stres ve büyüme değişkenlerini bir arada ele alan sınırlı sayıda araştırmaya rastlanırken bu konuda bir derleme çalışmasına rastlanmamıştır. Bu kapsamda yapılan çalışmanın literatürdeki boşluğu doldurarak literatüre önemli bir katkı sağlayacağı düşünülmektedir. Dolayısıyla gerçekleştirilen bu çalışmanın amacı, Türkiye'de travma sonrası stres ve büyüme konusunda gerçekleştirilmiş olan çalışmaları sistematik bir şekilde incelemektir.

\section{Yöntem}

\section{Araştırma Modeli}

Bu araştırma, Türkiye'de travma sonrası stres ve büyüme konusunda gerçekleştirilmiş olan çalışmaların ve bu çalışmaların sonuçlarının incelenmesi yönünden sistematik derleme çalışmasıdır. Derleme çeşitlerinden birisi olan sistematik derleme; benzer yöntemler ile yapılmış çok sayıdaki araştırmanın yapılandırılmış ve kapsamlı bir şekilde taranması, çeşitli dâhil edilme ve hariç tutulma kriterlerinin göz önünde bulundurulması ve nihayetinde araştırmaların çalışma grubuna dâhil edilmesi ve araştırmalarda yer alan bulguların sentez edilmesiyle gerçekleştirilen çalışmalar olarak tanımlanabilmektedir (Karaçam, 2013). Bu bağlamda yapılan bu çalışmada, YÖKTEZ ve ULAKBİM veri tabanlarında taramalar gerçekleştirilmiştir. Çeşitli dâhil edilme kriterleri gözetilerek taranan çalışmalar araştırma kapsamında değerlendirilmiştir. Dahil edilen çalışmalar doküman analizi yöntemi ile analiz edilmiştir. Doküman analizi yöntemi; araştırılması hedeflenen olgu veya olgular hakkındaki bilgileri içeren yazılı materyallerin incelenmesine dayanan bir yöntemdir (Yıldırım ve Şimşek, 2016). 


\section{Çalışma Grubu}

Araştırmanın çalışma grubunu, travma sonrası stres ve büyüme konusunda 2012-2021 yılları arasında YÖKTEZ ve ULAKBİM veri tabanlarında bulunan 6 makale ve 18 tez çalışması oluşturmaktadır.

\section{Veri Toplama Araci}

Araştırma sürecinde makale ve tezlerin incelenmesi için "Araştırma Değerlendirme Formu" kullanılmıştır. Bu form ile araştırma kapsamında incelenecek olan makale ve tezlerin belirli bir sistematiğe göre incelenmesi amaçlanmıştır. Böylece araştırmanın geçerlik ve güvenirliğinin artırılması hedeflenmiştir (Büyüköztürk, Kılıç Çakmak, Akgün, Karadeniz ve Demirel (2019). Araştırma değerlendirme formunun oluşturulmasında ilgili alanda araştırmalar yürüten 2 uzman görüşünden yararlanılmıştır. Formda; araştırmanın yazarları, araştırmanın başlığı, araştırmanın yılı, araştırmanın türü, araştırma modeli, çalışma grubu, çalışma grubunun büyüklüğü, lisansüstü tezin türü ve yayımlandığı enstitü, araştırmada kullanılan değişkenler olmak üzere 10 kategori yer almıştır.

\section{İşlem}

Araştırma kapsamında çalışma grubunun belirlenmesinde PRISMA raporundan (Moher, Liberati, Tetzlaff ve Altman, 2009) yararlanılarak yapılandırılmış bir literatür taraması gerçekleştirilmiştir. Literatür taraması 24 Mayıs-15 Haziran 2021 tarihleri arasında YÖKTEZ ve ULAKBIM veri tabanlarında yayımlanmış olan lisansüstü tez ve araştırma makalelerini kapsayacak şekilde Türkçe gerçekleştirilmiştir. Travma sonrası stres ve büyüme kapsamında gerçekleştirilen çalışmaları belirleyebilmek amaciyla "travma sonrası stres", "posttravmatik stres", "post travmatik stres", "travma sonrası büyüme" ve "travma sonrası gelişim" anahtar kelimeleri kullanılmıştır. Tablo 1'de alanyazın taramasında kullanılan anahtar kelimeler verilmiştir. 
Türkiye'de Travma Sonrası Stres ve Büyüme Konusunda Gerçekleştirilmiş Olan Çalışmaların İncelenmesi

Tablo 1. Alanyazin taramasinda kullanilan anahtar kelimeler

\begin{tabular}{llll}
\hline Veritabanı & Arama Kelimeleri & Doküman Türü & Tam Metin \\
\hline ULAKBIM & "Travma sonrası stres" & Araştırma makalesi & + \\
& "Posttravmatik stres" & \\
& "Post travmatik stres" & \\
& "Travma sonrası büyüme" & \\
YÖKTEZ & "Travma sonrası gelişim" & \\
& "Travma sonrası stres" & Lisansüstü tezler & + \\
& "Posttravmatik stres" & \\
& "Post travmatik stres" & \\
& "Travma sonrası büyüme" & \\
& "Travma sonrasi gelişim" & \\
\hline
\end{tabular}

Literatür taraması sonucunda çalışma grubunun belirlenmesinde çeşitli dâhil edilme kriterlerine dikkat edilmiştir. Çalışmanın dâhil edilme kriterleri Tablo 2' de belirtilmiştir.

Tablo 2. Araştırmaların dahil edilme kriterleri

\section{Dahil Edilme Kriterleri}

Başlığında travma sonrası stres ve büyümeyi (gelişmeyi) içeren araştırma makaleleri ve lisansüstü tezleri çalışmaya dahil edilmiştir.

ULAKBIM veri tabanında yer alan araştırma makaleleri ile YÖKTEZ veri tabanında yer alan lisansüstü tezler araştırma kapsamına alınmıştır.

Araştırma kapsamında 2012-2021 yılları arasında yayımlanmış çalışmalar araştırmaya dahil edilmiştir.

Tam metnine erişim izni olan lisansüstü tezleri ile araştırma makaleleri çalışma kapsamına alınmıştır.

Yapılan alanyazın taraması sonucunda toplam 842 araştırmaya ulaşılmıştır. Ulaşılan araştırmalar içinde dahil edilme kriterleri göz önünde bulundurularak 18 lisansüstü tez ile 6 araştırma makalesi çalışma kapsamına dâhil edilmiştir. Araştırma kapsamında incelenen çalışmaların künyelerine ilişkin bilgiler Tablo 3'te gösterilmiştir. 
Tablo 3. Araştırma kapsamında incelenen çalışmalar

\begin{tabular}{|c|c|c|}
\hline Yazar, Yil & Başlık & Araştırma Türü \\
\hline Elçi, 2021 & $\begin{array}{l}\text { Predictive factors of posttraumatic stress and posttraumatic growth among } \\
\text { the survivors of Van, 2011, earthquakes' trauma } \\
\text { Van depremlerini yaşayanlarda travma sonrası stres ve travma sonrası } \\
\text { büyümeyi yordayan faktörler }\end{array}$ & Lisansüstü Tez \\
\hline Acar, 2020 & $\begin{array}{l}\text { Suriyeli mültecilerde travma sonrası stres belirtileri ve travma sonrası } \\
\text { büyüme ile ilişkili değişkenler }\end{array}$ & Lisansüstü Tez \\
\hline $\begin{array}{l}\text { Özcan ve Arslan, } \\
2020\end{array}$ & $\begin{array}{l}\text { Travma sonrası stres ile travma sonrası büyüme arasındaki ilişkide sosyal } \\
\text { desteğin ve maneviyatın aracı rolü }\end{array}$ & Araştırma Makalesi \\
\hline Yeken, 2019 & $\begin{array}{l}\text { Posttraumatic stress disorder and posttraumatic growth in refugee } \\
\text { adolescents: Risks and protective factors }\end{array}$ & Lisansüstü Tez \\
\hline
\end{tabular}
adolescents: Risks and protective factors Mülteci ergenlerde travma sonrası stres bozukluğu ve travma sonrası büyüme: Riskler ve koruyucu faktörler

Haspolat, 2019 Travma sonrası stres belirtileri ve travma sonrası büyüme: Temel

Lisansüstü Tez

Gökhan, 2019 Posttraumatic stress and posttraumatic growth in the aftermath of terrorism: Lisansüstü Tez The roles of exposure, media, world assumptions, coping, and rumination Terör olaylarının ardından travma sonrası stres ve travma sonrası gelişim: Maruz kalmanın, medyanın, dünyaya ilişkin varsayımların, baş etmenin ve ruminasyonların rolü

Acet, 2019 Yetişkinlerde travma sonrası stres belirtileri ve travma sonrası gelişim: Otobiyografik bellek, dönüşmüş benlik ve bilinçli-yeniden değerlendirme modelleri kapsamında bir inceleme

Köskün, 2019 Yakınları intihar eden kişilerde travma sonrası stres belirtileri ve travma sonrası gelişim ile ilişkili değişkenler

Cengiz, Ergün ve Suriyeli sığınmacılarda travma sonrası stres bozukluğu, travma sonrası Çakıcı, 2019 büyüme ve ruhsal dayanıklılık: Hatay, Türkiye

Özcan, 2019 Yetişkinlerde travma sonrası stres ve öz duyarlılığın travma sonrası büyüme Araştırma Makalesi üzerindeki yordayıcı rolü

Yaman, 2018 The role of event centralıty and solıdarıty in the predıctıon of posttraumatıc Lisansüstü Tez stress and posttraumatic growth among the survivors of $10^{\text {th }}$ october terrorist attack

Olayın merkeziyeti ve dayanışmanın 10 ekim terör saldırısı'nda hayatta

kalanların travma sonrası stress ve travma sonrası büyüme düzeyleri üzerindeki yordayıcı rolü

Yanık, 2018 The mediating effect of rumination in relation to centrality of event, posttraumatic growth and posttraumatic stress disorder among breast

Lisansüstü Tez cancer survivors

Meme kanserini yenen kişilerde travma sonrası büyüme ve travma sonrası stres bozukluğu ile olayın merkeziyeti arasındaki ilişkide ruminasyonun araci etkisi

Tekcan, 2018

Yetişkinlerde travma sonrası stres belirtileri ile travma sonrası büyüme arasındaki ilişkide öz-şefkatin düzenleyici rolü

Şahne, 2018 Atatürk Havalimanı saldırısından 6 ay sonra personelde görülen travma

Acar ve Dirik, 2018 Yazılı duygusal dışavurum paradigması: kanser hastalarının eşlerinde

Lisansüstü Tez

Lisansüstü Tez

Araştırma Makalesi travma sonrası stres belirtileri ve travma sonrası gelişim üzerindeki etkileri

Gökler Danışman,

Tarhan Uçar ve

Okay, 2018

Eş şiddeti nedeniyle kadın konukevlerinde kalmakta olan kadınlarda travma sonrası stres ve travma sonrası gelişimin incelenmesi

Araştırma Makalesi

Kardaş ve Tanhan, Van depremini yaşayan üniversite öğrencilerinin travma sonrası stres, 2018

Kaçan, 2017 travma sonrası büyüme ve umutsuzluk düzeylerinin incelenmesi The path from traffic accident to posttraumatic stress, posttraumatic growth, Lisansüstü Tez and driver behavior change: An examination with rumination and transtheoretical model Trafik kazasından travma sonrası stres, travma sonrası gelişim ve sürücü 
Türkiye'de Travma Sonrası Stres ve Büyüme Konusunda Gerçekleştirilmiş Olan Çalışmaların İncelenmesi

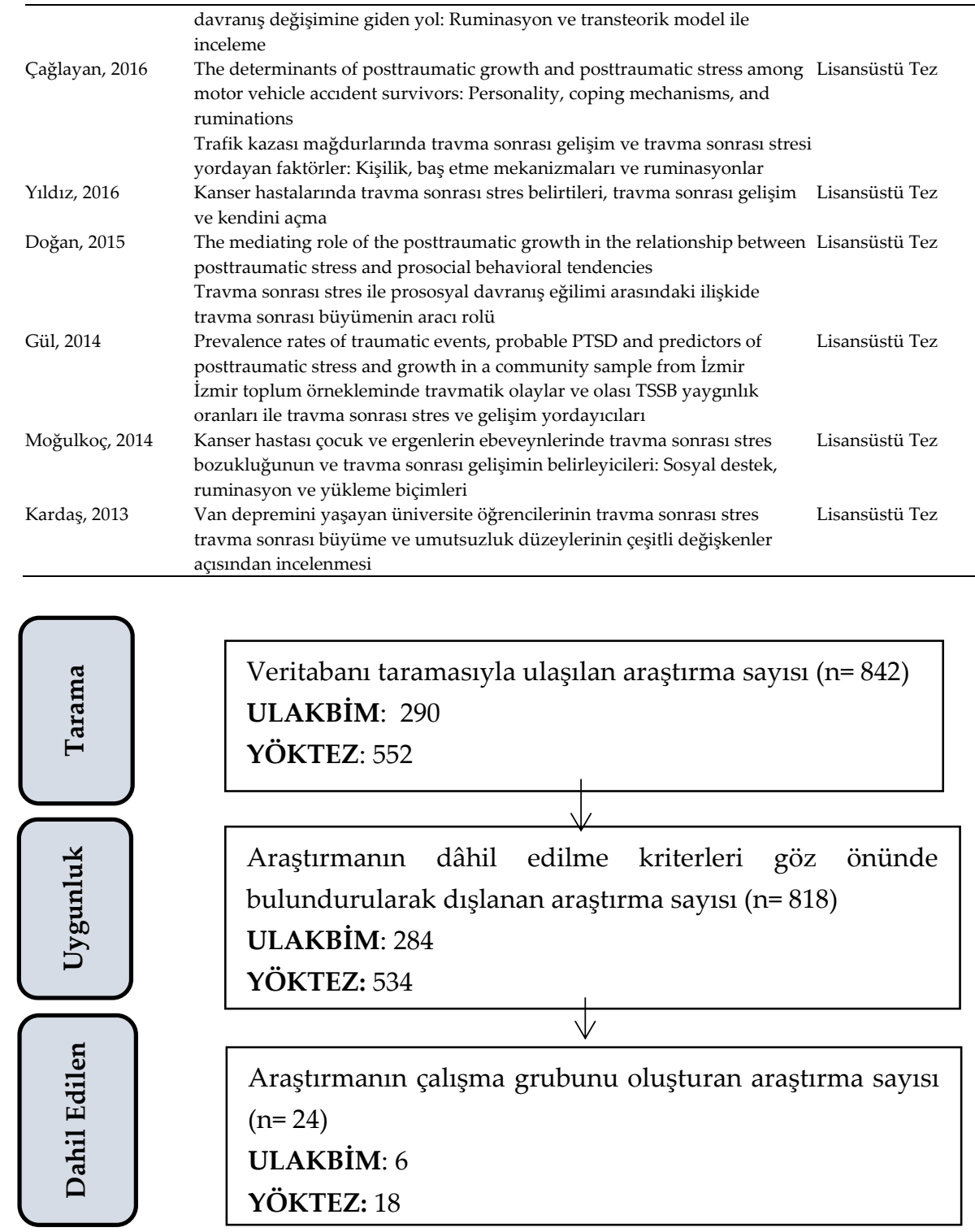

Şekil 1. Dokümanlarn Belirlenmesi ve Seçimine Yönelik Aşamaları Gösteren Akış Diyagramı.

Araştırma kapsamında, makale ve tezlerin belirlenmesi ve seçimine yönelik aşamalara ilişkin akış diyagramı Şekil 1'de verilmiştir 


\section{Bulgular}

Türkiye'de travma sonrası stres ve büyümeyi ele alan lisansüstü tezler ve makaleler yapıldıkları yıllara, araştırma yöntemlerine, çalışma gruplarına ve çalışma gruplarının genişliğine göre analiz edilmiştir. Tezler kendi içerisinde türlerine ve yapıldıkları enstitülere göre incelenmiştir. Ayrıca çalışmalarda travma sonrası stres ve büyüme ile birlikte kullanılan değişkenler de analize tabi tutulmuştur.

Tablo 4. Çalışmaların yayımlanma yıllarına göre dağılımları

\begin{tabular}{llllc}
\hline Yllar & Tezler & Makaleler & f & $\%$ \\
\hline 2012 & 0 & 0 & 0 & $\% 0$ \\
2013 & 1 & 0 & 1 & $\% 4.2$ \\
2014 & 2 & 0 & 2 & $\% 8.3$ \\
2015 & 1 & 0 & 1 & $\% 4.2$ \\
2016 & 2 & 0 & 2 & $\% 8.3$ \\
2017 & 1 & 0 & 1 & $\% 4.2$ \\
2018 & 4 & 3 & 7 & $\% 29.2$ \\
2019 & 5 & 2 & 7 & $\% 8.3$ \\
2020 & 1 & 1 & 2 & $\% 4.2$ \\
2021 & 1 & 0 & 1 & \\
\hline
\end{tabular}

Tablo 4'te araştırma kapsamında incelenen lisansüstü tez ve makalelerin yayımlanma yıllarına göre dağılımları verilmiştir. Tablo 4 incelendiğinde; 2013, 2015, 2017, 2021 yillarında 1'er (\%4.2), 2014, 2016, 2020 yıllarında 2'şer (\%8.3), 2018 ve 2019 yıllarında ise 7'şer (\% 29.2) çalışmanın yayımlandığı görülmüştür. Araştırmanın bu bulgusuna göre travma sonrası stres ve büyüme konusunda en çok çalışmanın 2018 ve 2019 yılları arasında yapıldığı söylenebilmektedir.

Tablo 5. Çalışmaların araştırma yöntemine göre dağılımları

\begin{tabular}{llllc}
\hline Yöntem & Tezler & Makaleler & f & \% \\
\hline Nicel Yöntem (Betimsel, ilişkisel vb.) & 18 & 6 & 24 & $\% 100$ \\
Nitel Yöntem & 0 & 0 & 0 & $\% 0$ \\
\hline
\end{tabular}

Tablo 5'te araştırma kapsamında incelenen lisansüstü tez ve makalelerin araştırma yöntemine göre dağılımları verilmiştir. Tablo 5 incelendiğinde çalışmaların tamamının (24, \%100) nicel araştırma yöntemi ile gerçekleştirildiği görülmektedir. Çalışmalarda ayrıca nicel araştırma yöntemleri içinde yer alan korelasyonel araştırma, genel 
tarama modeli, ilişkisel tarama modeli, betimsel tarama modellerinin kullanıldı ̆̆ 1 belirtilmektedir.

Tablo 6. Çalışma gruplarına göre dağılımları

\begin{tabular}{llllc}
\hline Çalışma grupları & Tezler & Makaleler & f & \% \\
Ergenler & 1 & 0 & 1 & $\% 4.2$ \\
Yetişkinler & 15 & 5 & 20 & $\% 83.3$ \\
Üniversite Öğrencileri & 2 & 1 & 3 & $\% 12.5$ \\
\hline
\end{tabular}

Tablo 6'da araştırma kapsamında incelenen lisansüstü tez ve makalelerin çalışma gruplarına göre dağılımları verilmiştir. Tablo 6 incelendiğinde araştırmalardan 1'inin (\%4.2) ergenler, 20'sinin (\%83.3) yetişkinler ve 3'ünün (\%12.5) üniversite öğrencileriyle gerçekleştirildiği görülmektedir. Araştırmanın bu bulgusuna göre literatürde rastlanan çalışmaların çoğunluğunun yetişkinlerle yapıldığı söylenebilmektedir.

Tablo 7. Çalışma grubu genişliğine göre dă̆ılımları

\begin{tabular}{lllll}
\hline Çalışma Grubu Genişliği & Tezler & Makaleler & f & \% \\
\hline $0-100$ & 3 & 1 & 4 & $\% 16.7$ \\
$101-200$ & 3 & 1 & 4 & $\% 16.7$ \\
$201-300$ & 4 & 0 & 4 & $\% 16.7$ \\
$301-400$ & 3 & 1 & 4 & $\% 16.7$ \\
$401-600$ & 1 & 1 & 2 & $\% 8.3$ \\
$601-800$ & 3 & 1 & 4 & $\% 16.7$ \\
800 ve üzeri & 1 & 1 & 2 & $\% 8.3$ \\
\hline
\end{tabular}

Tablo 7'de araştırma kapsamında incelenen lisansüstü tez ve makalelerin çalışma grubu genişliğine göre dağılımları verilmiştir. Tablo 7 incelendiğinde 4 (\%16.7) araştırmanın $1-100$ kişi, 4 (\%16.7) araştırmanın 101-200 kişi, 4 (\%16.7) araştırmanın 201-300 kişi, 4 (\%16.7) araştırmanın 301-400 kişi, 2 (\%8.3) araştırmanın 401-600 kişi, 4 (\%16.7) araştırmanın 601-800 kişi, 2 (\%8.3) araştırmanın 800 ve üzeri kişi ile gerçekleştirildiği görülmüştür. Araştırmanın bu bulgusuna göre çalışma grubu genişliklerinin araştırmalar arasında dikkate değer farklılık gösterdiği söylenebilmektedir.

Tablo 8. Lisansüstü tezlerin türlerine göre dağılımları

\begin{tabular}{lll}
\hline Tez Türü & $\mathbf{f}$ & $\mathbf{\%}$ \\
\hline Yüksek Lisans & 14 & $\% 77.8$ \\
Doktora & 4 & $\% 22.2$ \\
\hline
\end{tabular}


Tablo 8'de araştırma kapsaminda lisansüstü tezlerin türlerine göre dağılımları verilmiştir. Tablo 8 incelendiğinde; 14 (\%77.8) araştırmanın yüksek lisans tezi ve $4(\% 22.2)$ araştırmanın doktora tezi olduğu görülmüştür. Bu bulguya göre travma sonrası stres ve büyümeye dair gerçekleştirilen araştırmaların çoğunlukla yüksek lisans düzeyinde gerçekleştirildiği söylenebilmektedir.

Tablo 9. Lisansüstü tezlerin enstitülere göre dağılımlarn

\begin{tabular}{lll}
\hline Enstitüler & f & $\%$ \\
\hline Sosyal Bilimler Enstitüsü & 17 & $\% 94.4$ \\
Eğitim Bilimleri Enstitüsü & 1 & $\% 5.6$ \\
\hline
\end{tabular}

Tablo 9'da araştırma kapsamında lisansüstü tezlerin enstitülere göre dağılımları verilmiştir. Tablo 9 incelendiğinde; 17 (\%94.4) araştırmanın sosyal bilimler enstitüsünde ve 1 (\%5.6) araştırmanın eğitim bilimleri enstitüsünde yapıldığ1 görülmüştür. Bu bulguya göre 2012-2021 yılları arasında travma sonrası stres ve büyümeye dair gerçekleştirilen araştırmaların tamamına yakınının sosyal bilimler enstitüsünde gerçekleştirildiği söylenebilmektedir.

Tablo 10. Çalışmalarda travma sonrası stres ve büyüme ile birlikte kullanılan değişkenlerin dağılımları

\begin{tabular}{llllll}
\hline Değişken & f & \% & Değişken & f & $\%$ \\
\hline Sosyo-Demografik & 24 & $\% 100$ & Dünyaya ilişkin varsayımlar & 2 & $\% 8.3$ \\
Ruminasyon & 8 & $\% 33.3$ & Travma sonrası biliş & 1 & $\% 4.2$ \\
Baş Etme & 6 & $\% 25$ & Yaşam yönelimi & 1 & $\% 4.2$ \\
Sosyal Destek & 5 & $\% 20.8$ & Manevi yönelim & 1 & $\% 4.2$ \\
Ego resilince/sağlamlık/dayanıklılık & 3 & $\% 12.5$ & Yükleme biçimleri & 1 & $\% 4.2$ \\
Travmatik yaşantılar & 3 & $\% 12.5$ & Olumlu yeniden değerlendirme & 1 & $\% 4.2$ \\
Temel inançlar & 3 & $\% 12.5$ & Prososyal davranış eğilimi & 1 & $\% 4.2$ \\
Olayın merkeziyeti & 3 & $\% 12.5$ & Anksiyete & 1 & $\% 4.2$ \\
Olaya ilişkin faktörler & 3 & $\% 12.5$ & Depresyon & 1 & $\% 4.2$ \\
Göç/iltica sonrası yaşanan zorluklar & 2 & $\% 8.3$ & Kendini açma & 1 & $\% 4.2$ \\
Umutsuzluk & 2 & $\% 8.3$ & Olaya ilişkin faktörler & 1 & $\% 4.2$ \\
Kişilik özellikleri & 2 & $\% 8.3$ & Transteorik model & 1 & $\% 4.2$ \\
Bilinçli farkındalık & 2 & $\% 8.3$ & Yazılı duygusal dı̧̧avurum & 1 & $\% 4.2$ \\
Sürücü davranışları & 2 & $\% 8.3$ & Dayanışma & 1 & $\% 4.2$ \\
Öz şefkat/öz duyarlık & 2 & $\% 8.3$ & İntihara ilişkin tutumlar & 1 & $\% 4.2$ \\
\hline
\end{tabular}

Tablo 10 'da lisansüstü tez ve makalelerde travma sonrası stres ve büyüme ile birlikte kullanılan değişkenlerin dağılımları verilmiştir. Tablo 10 incelendiğinde; 24 (\%100) araştırmada sosyo-demografik 
değişkenlerin, 8 (\%33.3) araştırmada ruminasyon değişkeninin, 6 (\%25) araştırmada baş etme değişkeninin, 5 (\%20.8) araştırmada sosyal destek değişkeninin, $\quad 3$ 'er $\quad(\% 12.5) \quad$ araştırmada ego resilince/sağlamlık/dayanıklılık, travmatik yaşantılar, temel inançlar, olayın merkeziyeti, olaya ilişkin faktörler değişkenlerinin, 2'şer (\%8.3) araştırmada göç/iltica sonrası yaşanan zorluklar, umutsuzluk, kişilik özellikleri, bilinçli farkındalık, sürücü davranışları, öz şefkat/öz duyarlık, dünyaya ilişkin varsayımlar değişkenlerinin, 1'er (\%4.3) araştırmada travma sonrası biliş, yaşam yönelimi, manevi yönelim, yükleme biçimleri, olumlu yeniden değerlendirme, prososyal davranış eğilimi, anksiyete, depresyon, kendini açma, olaya ilişkin faktörler, transteorik model, yazılı duygusal dişavurum, intihara ilişkin tutumlar ve dayanışma değişkenlerinin incelendiği görülmüştür. Bu bulguya göre ulaşılan lisansüstü tez ve makalelerde ruminasyon, baş etme, sosyal destek ve sosyo-demografik değişkelerin travma sonrası stres ve büyüme ile birlikte en fazla kullanılan değişkenler olduğu söylenebilmektedir.

\section{Tartışma ve Sonuç}

Bu araştırmada Türkiye'de travma sonrası stres ve büyüme konusunda gerçekleştirilmiş olan çalışmaların sistematik bir şekilde incelenmesi amaçlanmıştır. Bu kapsamda 2012-2021 yılları arasında yayımlanmış olan 18 lisansüstü tez ve 6 araştırma makalesi yayımlanma yılı, araştırma yöntemi, çalışma grupları, çalışma gruplarının genişliği, lisansüstü tezlerin türleri ve yayımlandıkları enstitüler, travma sonrası stres ve büyüme ile birlikte kullanılan değişkenlerin dağılımlarına göre incelenmiştir.

Araştırma kapsamında incelenen lisansüstü tez ve araştırma makalelerinin çoğunun 2018 ve 2019 yılları arasında yapıldığı görülmüştür. Bu bağlamda incelenen 24 çalışmanın 14'ünün 2018 ve 2019 yıllarında yayımlandığı tespit edilmiştir. Bu durumda giderek artan travmatik yaşantıların (Özcan, 2019) ve bu kavramlara olan ilginin artmasının (Köskün, 2019; Tekcan, 2018), araştırmacıların ilgili çalışmaların azlığına yönelik farkındalıklar geliştirilmesinin (Acar ve Dirik, 2018; Cengiz vd., 2019) etkili olduğu düşünülmektedir. 
Araştırma sonucunda incelenen lisansüstü tez ve makalelerin tamamının nicel araştırma yöntemi ile gerçekleştirildiği görülmüştür. Bu durumda nitel araştırma yöntemleri ile gerçekleştirilen çalışmaların nicel araştırma yöntemlerine göre daha çok vakit alması (Arık ve Türkmen, 2009), daha öznel olması (Baltacı, 2019), genellenememesi (Yaşar, 2018) gibi durumlar etkili olmuş olabilir.

Araştırma kapsamında incelenen lisansüstü tez ve makalelerin çoğunlukla yetişkinlerle gerçekleştirildiği görülmüştür. Tedeschi ve Calhoun (2004) çalışmalarında travma sonrası büyümenin, travma sonrasında değişen bir dizi yerleşik şemaları içerdiğinden dolayı çocuklardan ziyade yetişkinlerle çalışmalarda daha uygulanabilir bir yapı oluşturduğunu belirtmişlerdir. Ayrıca travma sonrası stres ile ilgili çalışmalarda travmanın çocuklar üzerindeki belirtilerinin klinik bir bozukluk düzeyine ulaşmadan da uzun süre devam edebilmesinden (Kılıç, Uslu, Erden ve Kerimoğlu, 2007) ve tanılanan çocukların stres tepkilerini dışavurumlarının gelişimsel dönem özelliklerine göre değişebilmesinden (Oflaz, 2015) dolayı çocuklarla yapılan çalışmaların güçlükler oluşturabileceği değerlendirilmektedir. Bu durum, travma sonrası stres ve büyüme konusunda yapılan çalışmaların çok büyük bir bölümünün yetişkinlerle gerçekleştirilmesini açılar niteliktedir.

Araştırma kapsamında incelenen lisansüstü tez ve makalelerin çalışma grubu genişliğine göre dağılımları incelendiğinde 40 kişi (1-100 arasında) ile yapılan araştırma olduğu gibi 1059 kişi (800 ve üzeri) ile de yapılan araştırmanın olduğu görülmüştür. Bu kapsamda çalışma grubu genişliklerinin araştırmalar arasında dikkate değer farklılıklar gösterdiği fark edilmiştir. Araştırmalarda konu edinilen intihar (Köskün, 2019), deprem (Kardaş ve Tanhan, 2018), terör (Gökhan, 2019), şiddet (Gökler Danışman vd., 2018), saldırı (Şahne, 2018), kaza (Çağlayan, 2019), kanser (Acar ve Dirik, 2018; Moğolkoç, 2014; Yıldız, 2016), göç (Yeken, 2019) gibi travmatik yaşam olaylarının çeşitliğinin, araştırmaların dahil edilme kriterlerinin (Yanık, 2018) ve çalışma grubunun ulaşılabilirliğinin (Kardaş, 2013) bu farklılıkta etkili olduğu düşünülmektedir.

Lisansüstü tezlerin incelenmesinde travma sonrası stres ve büyümeye dair gerçekleştirilen araştırmaların çoğunlukla yüksek lisans düzeyinde gerçekleştirildiği görülmüştür. Ülkemizde genelde yüksek lisans 
eğitiminin devamında doktora eğitimine geçiş oranı düşük olduğu için bu sonuç normal olarak değerlendirilmiştir (Türe ve Barut, 2020).

Araştırma kapsamında 2012-2021 yılları arasında travma sonrası stres ve büyümeye dair gerçekleştirilen araştırmaların tamamına yakınının sosyal bilimler enstitüsünde gerçekleştirildiği tespit edilmiştir. Bu durumda travma sonrası stres ve büyümenin psikolojik bir kavram olması ve psikoloji anabilim dalının sosyal bilimler enstitüsünde yer almasının etkili olduğu düşünülmektedir. Bu açıklamaya paralel bir şekilde konuyla ilgili tüm çalışmaların psikoloji alanında gerçekleştirildiği görülmüştür. Travmanın, bireyi ruhsal ve bedensel olarak etkileyen (Jones ve Wessely, 2007; Kokurcan ve Özsan, 2012) bireylerin duygu, düşünce ve ruhsal durumlarını uzun süre etkisi altına alan olaylar olarak (Özen, 2017) ifade edilmesi yapılan çalışmaların psikoloji alanında ve sosyal bilimler enstitüsünde gerçekleştirilmesini açıklar niteliktedir.

Araştırma kapsamında lisansüstü tez ve makalelerde travma sonrası stres ve büyüme ile birlikte sosyo-demografik değişkenlerin (24 araştırmada), ruminasyon değişkeninin (8 araştırmada), baş etme değişkeninin (6 araştırmada) ve sosyal destek değişkeninin (5 araştırmada) en fazla kullanılan değişkenler olduğu görülmüştür.

Schaefer ve Moos (1992), sosyo-demografik değişkenlerin, kişisel faktörlerin, sosyal destek ve bireyin yaşam koşullarından oluşan çevresel faktörlerin, olaya ilişkin faktörlerin ve baş etme stratejilerinin travma sonrası büyümede önemli faktörler olduğunu belirtmişlerdir. Calhoun ve Tedeschi (2004), travma sonrası büyümede kişilik özellikleri, ruminasyon, baş etme yolları ve sosyal destek faktörleri üzerinde durmuşlardır. Udwin, Boyle, Yule, Bolton ve O'Ryan (2000) sosyal destek değişkenini travma sonrası stres bozukluğu geliştirmede önemli bir değişken olarak görmüşlerdir. Ayrıca yapılan çalışmalar, travmatik deneyimler sonucunda travma sonrası stres bozukluğu gibi olumsuz tepkiler ya da travma sonrası büyüme gibi olumlu değişimler yaşanmasında kişinin dünyaya, diğer insanlara ve kendisine ilişkin temel inançlarının sarsılmasının, bu sarsıntının tetiklediği olaya ilişkin ruminasyonların (istemli ve istemsiz ruminasyonlar) ve bunlar gibi bilişsel süreçlerin belirleyici olduğunu ortaya koymuştur (Haspolat, 2019). Bununla birlikte Chan, Medicine, Air ve McFarlane, (2003), 
travmayla karşılaşan bireylerin travmaya nasıl tepkiler vereceği ve travmanın etkilerinin ileride ruhsal bir bozukluğa dönüşüp dönüşmeyeceğinde; travmanın şiddetinin yanı sıra kişinin genetik yatkınlığı ve aile öyküsü, stresle başa çıkma yöntemleri, sosyal destek kaynakları, geçmiş travma ve stres yaşantıları gibi faktörlerin etkili olabileceğini belirtmişlerdir (Yıldız, 2016). Bu açıklamalar ve araştırmaların, gerçekleştirilen çalışmada travma sonrası stres ve büyüme ile birlikte en fazla kullanılan değişkenlerin ruminasyon, baş etme, sosyal destek ve sosyo-demografik değişkenler olmasına paralel bir yapı arz ettiği söylenebilir.

Bu araştırma, Türkiye'de travma sonrası stres ve büyüme konusunda gerçekleştirilmiş olan lisansüstü tez ve araştırma makalelerinin belirli kriterler çerçevesinde incelenmesine dayanan sistematik bir derleme çalışmasıdır. $\mathrm{Bu}$ bağlamda araştırmada yalnızca Türkiye'de gerçekleştirilmiş olan lisansüstü tez ve makaleler incelenmiştir. Bundan sonra yapılacak araştırmalara yurt dışında gerçekleştirilmiş olan çalışmalar da dahil edilerek daha kapsamlı tarama süreçleri gerçekleştirilebilir. $\mathrm{Bu}$ araştırmada lisansüstü tez ve makaleler; araştırmanın yılı, araştırmanın türü, araştırma yöntemi, çalışma grubu, çalışma grubunun büyüklüğü, tez türü, tezin yayımlandığ1 enstitü, araştırmada kullanılan değişkenler açısından incelenmiştir. İlerleyen araştırmalarda farklı ölçütlerde işe katılarak çalışmalar gerçekleştirilebilir. $\mathrm{Bu}$ araştırma doküman analizi yöntemi ile gerçekleştirilmiştir. Bu kapsamda gelecekte yapılacak çalışmalarda farklı yöntemler kullanılarak çalışmalar yürütülebilir. Ayrıca bu çalışmada travma sonrası stres ve büyümenin ele alındığı tüm çalışmaların nicel araştırma yöntemi ve genel olarak tarama modeliyle gerçekleştirildiği görülmüştür. İlerleyen çalışmalarda bu ve benzeri araştırmaların çıktılarından yararlanılarak psikoeğitim programları gerçekleştirilebilir ve bu programlara yönelik deneysel ve nitel araştırmalar yapılabilir. 


\title{
EXTENDED ABSTRACT
}

\section{A Review of Studies on Post-Traumatic Stress and Growth Carried in Turkey}

\author{
Esra Teke- Selahattin Avşaroğlu \\ Necmettin Erbakan University
}

The fact that individuals exposed to the traumatic event continue to experience these symptoms with the severity of the first day even after a long time has passed (Davison and Neale, 2004; Deblinger, Steer and Lippmann, 1999) and this situation becomes chronic is expressed as posttraumatic stress disorder (Işıklı and Keser, 2020).

As a result of traumatic events, individuals may lose their confidence and sense of safety for the future, and they may experience a sense of instability and loss of control as a result of excessive emotional reactions to threats (Bergner, 2009). However, there are also research suggesting that some positive outcomes may occur after a traumatic experience (İnci and Boztepe, 2013). In the literature, the positive psychological change that occurs as a result of individuals' struggle with difficult life experiences is defined as post-traumatic growth (Tedeschi and Calhoun, 2004).

As a result of conceptual explanations, post-traumatic growth and post-traumatic stress are considered as opposite concepts. However, when the research in the literature is examined, it has been found that there are studies showing that there is a positive relationship between these two variables (Solomon and Dekel, 2007; Tekcan, 2018). However, there are also findings in the literature that there is a negative relationship between these two variables (Frazier, Conlon and Glaser, 2001) or that there is no significant relationship (Salsman, Segerstrom, Brechting, Carlson and Andrykowski, 2009).

The purpose of the current research is to examine systematically the studies on post-traumatic stress and growth in Turkey. In the research, graduate thesis and research articles published on post-traumatic stress and growth were scanned in a comprehensive and structured way. In this context, the findings of the research were synthesized by considering 
various inclusion and exclusion criteria. The research is a systematic review study and was carried out by document analysis method. In order to determine the study group of the research, 552 postgraduate theses and 290 articles published between 2012 and 2021 were reached in the searches performed in YÖKTEZ and ULAKBİM databases between 24 May and 15 June 2021. Considering the inclusion criteria, 18 postgraduate theses and 6 articles formed the study group of the research. The "Research Evaluation Form" prepared by the researchers was used in the examination of theses and articles in the study group. The studies were examined within the framework of the criteria of the year of the research, the type of the research, the research method, the study group, the size of the study group, the type of the graduate thesis and the institute where it was published, and the variables used in the research.

In the research it was noticed that most of the postgraduate theses and research articles examined within the scope of the research were made between 2018 and 2019. It was observed that all of them were carried out with the quantitative research method. In addition, these studies were mostly carried out with adults. When the distribution of these studies according to the size of the study group was examined, it was seen that there was a study with 40 people (between 1 and 100), as well as a study with 1059 people (800 and above). In this context, it was noticed that the size of the study group showed remarkable differences between studies. It has been determined that the studies are mostly carried out at the graduate level and almost all of them are carried out in the institute of social sciences. Besides, post-traumatic stress and growth, together with socio-demographic variables (24 studies), rumination variable (8 studies), coping variable (6 studies) and social support variable (5 studies) were the most frequently used variables in postgraduate theses and articles within the scope of the research.

In this research, only postgraduate theses and articles that were carried out in Turkey were examined. More comprehensive screening processes can be carried out by including studies carried out abroad in future research. In this research, postgraduate theses and articles; the year of the research, the type of the research, the research method, the 
study group, the size of the study group, the type of the thesis, the institute where the thesis was published, were examined in terms of the variables used in the research. In future research, studies can be carried out by engaging different criteria. This research was carried out by document analysis method. In this context, studies can be carried out using different methods in future studies. In addition, in this research, it was noticed that all studies dealing with post-traumatic stress and growth were carried out with the quantitative research method and the screening model in general. In future studies, psychoeducational programs can be performed by making use of the outputs of current and similar studies, and experimental and qualitative research can be conducted for these programs.

\section{Kaynakça/References}

Acar, B. (2020). Suriyeli mültecilerde travma sonrası stres belirtileri ve travma sonrası büyüme ile ilişkili değģşkenler. (Yayımlanmamış Yüksek Lisans Tezi). Marmara Üniversitesi, Sosyal Bilimler Enstitüsü, İstanbul.

Acar, D. ve Dirik, G. (2018). Yazılı duygusal dişavurum paradigması: Kanser hastalarının eşlerinde travma sonrası stres belirtileri ve travma sonrası gelişim üzerindeki etkileri. Klinik Psikiyatri Dergisi, 21(2), 154-167. doi: 10.5505/kpd.2018.48343ü.

Acet, P. (2019). Yetişkinlerde travma sonrası stres belirtileri ve travma sonrası gelişim: Otobiyografik bellek, dönüşmüş benlik ve bilinçli-yeniden değerlendirme modelleri kapsaminda bir inceleme. (Yayımlanmamış Yüksek Lisans Tezi). Dokuz Eylül Üniversitesi, Sosyal Bilimler Enstitüsü, İzmir.

Arık, R. S. ve Türkmen, M. (2009). Eğitim bilimleri alanında yayınlanan bilimsel dergilerde yer alan makalelerin incelenmesi. Uluslararası Türkiye Ĕ̆itim Araştırmaları Kongresi, Çanakkale Onsekiz Mart Üniversitesi, Antalya, 1-16.

Baltacl, A. (2019). Nitel araştırma süreci: Nitel bir araştırma nasıl yapılır?. Ahi Evran Üniversitesi Sosyal Bilimler Enstitüsü Dergisi, 5(2), 368-388. doi: 10.31592/aeusbed.598299.

Bergner, R. M. (2009). Trauma, exposure, and world reconstruction. American Journal of Psychotherapy, 63(3),

267-282. https://doi.org/10.1176/appi.psychotherapy.2009.63.3.267. 
Brewin, C. R. (2011). The nature and significance of memory disturbance in posttraumatic stress disorder. Annual Review of Clinical Psychology, 7, 203-227. https://doi.org/10.1146/annurev-clinpsy-032210-104544.

Büyüköztürk, Ş., Kılıç Çakmak, E., Akgün, Ö. D., Karadeniz, Ş. ve Demirel, F. (2019). Eğitimde bilimsel araştırma yöntemleri. Ankara: Pegem Akademi.

Carlson, E. B. ve Dalenberg, C. J. (2000). A conceptual framework for the impact of traumatic experiences. Trauma, Violence, $\mathcal{E}$ Abuse, 1(1), 4-28. https://doi.org/10.1177/1524838000001001002.

Cengiz, I., Ergün, D. ve Cakici, E. (2019). Posttraumatic stress disorder, posttraumatic growth and psychological resilience in Syrian refugees: Hatay, Turkey. Anadolu Psikiyatri Dergisi,20(3), 269-276. doi: 10.5455/apd.4862 .

Çağlayan, P. (2016). The determinants of posttraumatic growth and posttraumatic stress among motor vehicle accident survivors: Personality, coping mechanisms, and ruminations. (Yayımlanmamış Doktora Tezi). Orta Doğu Teknik Üniversitesi, Sosyal Bilimler Enstitüsü, Ankara.

Davison, G. C. ve Neale, J. M. (2004). Anormal psikolojisi (Abnormal psychology), (İ. Dağ, Çev.). Ankara: Türk Psikologlar Derneği Yayınları.

Deblinger, E., Steer, R. A. ve Lippmann, J. (1999). Two-year follow-up study of cognitive behavioral therapy for sexually abused children suffering post-traumatic stress symptoms. Child Abuse \& Neglect, 23(12), 13711378. https://doi.org/10.1016/S0145-2134(99)00091-5.

Doğan, F. (2015). The mediating role of the posttraumatic growth in the relationship between posttraumatic stress and prosocial behavioral tendencies. (Yayımlanmamış Yüksek Lisans Tezi). Orta Doğu Teknik Üniversitesi, Sosyal Bilimler Enstitüsü, Ankara.

Dunmore, E., Clark, D. M. ve Ehlers, A. (2001). A prospective investigation of the role of cognitive factors in persistent posttraumatic stress disorder (PTSD) after physical or sexual assault. Behaviour Research and Therapy, 39(9), 1063-1084. https://doi.org/10.1016/S0005-7967(00)00088$\underline{7}$

Ehlers, A. ve Clark, D. M. (2000). A cognitive model of posttraumatic stress disorder. Behaviour Research and Therapy, 38(4), 319-345. https://doi.org/10.1016/S0005-7967(99)00123-0.

Elçi, Ö. (2021). Predictıve factors of posttraumatıc stress and posttraumatıc growth among the survivors of van, 2011, earthquakes' trauma. (Yayımlanmamış 
Doktora Tezi). Orta Doğu Teknik Üniversitesi, Sosyal Bilimler Enstitüsü, Ankara.

Frazier, P., Conlon, A. ve Glaser, T. (2001). Positive and negative life changes following sexual assault. Journal of consulting and clinical psychology, 69(6), 1048-1055. doi:10.1037/0022-006X.69.6.1048.

Gökhan, K. (2019). Posttraumatic stress and posttraumatic growth in the aftermath of terrorism: the roles of exposure, media, world assumptions, coping, and rumination. (Yayımlanmamış Yüksek Lisans Tezi). Orta Doğu Teknik Üniversitesi, Sosyal Bilimler Enstitüsü, Ankara.

Gökler Danışman, I., Tarhan Uçar, C. ve Okay, D. (2018). Eş şiddeti nedeniyle kadın konukevlerinde kalmakta olan kadınlarda travma sonrası stres ve travma sonrası gelişimin incelenmesi. Anatolian Journal of Psychiatry/Anadolu Psikiyatri Dergisi, 19(6), 537-544. doi: 10.5455/apd.295318.

Gökmen, G. ve Deniz, M. (2020). Travma sonrası büyümenin yordayıcıları olarak öz-anlayış ve affetme. Uluslararası Türk Kültür Coğrafyasında Sosyal Bilimler Dergisi, 5(2), 72-93.

Gül, E. (2014). Prevalence rates of traumatic events, probable PTSD and predictors of posttraumatic stress and growth in a community sample from İzmir. (Yayımlanmamış Doktora Tezi). Orta Doğu Teknik Üniversitesi, Ankara.

Hapke, U., Schumann, A., Rumpf, H. J., John, U. ve Meyer, C. (2006). Posttraumatic stress disorder. European Archives of Psychiatry And Clinical Neuroscience, 256(5), 299-306. https://doi.org/10.1007/s00406-006-0654$\underline{6}$

Haspolat, A. (2019). Travma sonrası stres belirtileri ve travma sonrası büyüme: Temel inançlardaki değişim, ruminasyonlar ve bilgece farkındalı̆̆ı rolü. (Yayımlanmamış Yüksek Lisans Tezi). Başkent Üniversitesi, Sosyal Bilimler Enstitüsü, Ankara.

Işıklı S. ve Keser E. (2020). Travma sonrası stres bozukluğunda duygular ve duygu düzenleme. S. Vatan (Ed.), Duygu düzenleme (1. Baskl, s.55-63). Ankara: Türkiye Klinikleri.

İnci, F. ve Boztepe, H. (2013). Travma sonrası büyüme: Öldürmeyen acı güçlendirir mi?. Psikiyatri Hemşireliği Dergisi, 4(2), 80-84. doi: 10.5505/phd.2013.29392. 
Jones, E. ve Wessely, S. (2007). A paradigm shift in the conceptualization of psychological trauma in the 20th century. Journal of Anxiety Disorders, 21(2), 164-175. https://doi.org/10.1016/j.janxdis.2006.09.009.

Kaçan, B. (2017). The path from traffic accident to posttraumatic stress, posttraumatic growth, and driver behavior change: An examination with rumination and transtheoretical model. (Yayımlanmamış Yüksek Lisans Tezi). Orta Doğu Teknik Üniversitesi, Sosyal Bilimler Enstitüsü, Ankara.

Kanat, B. B. ve Özpolat, A. G. Y. (2016). Kanser hastalarında travma sonrası büyüme kavramı. Turkish Journal of Clinics and Laboratory, 7(4), 106110. https://dergipark.org.tr/en/pub/tjcl/issue/26304/286720.

Karaçam, Z. (2013). Sistematik derleme metodolojisi: Sistematik derleme hazırlamak için bir rehber. Dokuz Eylül Üniversitesi Hemşirelik Fakültesi Elektronik Dergisi, 6(1), 26-33. https://dergipark.org.tr/en/pub/deuhfed/issue/46815/587078.

Karaman, Ö. Ü. Ö. ve Tarım, A. G. B. (2018). Travma sonrası büyüme, sosyal problem çözme ve iyimserlik arasındaki ilişkilerin incelenmesi. Dicle Üniversitesi Sosyal Bilimler Enstitüsü Dergisi, 10(20), 190-198.

Kardaş, F. (2013). Van depremini yaşayan üniversite öğrencilerinin travma sonrası stres travma sonrası büyüme ve umutsuzluk düzeylerinin çeşitli değişkenler açısından incelenmesi. (Yayımlanmamış Yüksek Lisans Tezi). Yüzüncü Yıl Üniversitesi, Eğitim Bilimleri Enstitüsü, Van.

Kardaş, F. ve Tanhan, F. (2018). Van depremini yaşayan üniversite öğrencilerinin travma sonrası stres, travma sonrası büyüme ve umutsuzluk düzeylerinin incelenmesi. Yüzüncü Yıl Üniversitesi Eğitim Fakültesi Dergisi, 15(1), 1-36. http://dx.doi.org/10.23891/efdyyu.2018.60.

Kessler, R. C., Berglund, P., Demler, O., Jin, R., Merikangas, K. R. ve Walters, E. E. (2005). Lifetime prevalence and age-of-onset distributions of DSM-IV disorders in the National Comorbidity Survey Replication. Archives of General Psychiatry, 62(6), 593-602. doi:10.1001/archpsyc.62.6.593.

Kılıç, E. Z., Uslu, R. İ., Erden, G. ve Kerimoğlu, E. (2007). Çocuklarda travma sonrası stres bozukluğu belirtilerini sürdüren ailesel etmenler. Kriz Dergisi, 7(2), 1-8.

Kokurcan, A. ve Özsan, H. H. (2012). Travma kavramının psikiyatri tarihindeki seyri. Kriz Dergisi, 20(1-2-3), 19-24. 
Köskün, T. (2019). Yakınları intihar eden kişilerde travma sonrası stres belirtileri ve travma sonrası gelişim ile ilişkili değişkenler. (Yayımlanmamış Yüksek Lisans Tezi). Aydın Adnan Menderes Üniversitesi, Sosyal Bilimler Enstitüsü, Aydın.

Moğulkoç, H. (2014). Kanser hastası çocuk ve ergenlerin ebeveynlerinde travma sonrası stres bozukluğunun ve travma sonrası gelişimin belirleyicileri: Sosyal destek, ruminasyon ve yükleme biçimleri. (Yayımlanmamış Yüksek Lisans Tezi). Uludağ Üniversitesi, Sosyal Bilimler Enstitüsü, Bursa.

Moher, D., Liberati, A., Tetzlaff, J. ve Altman, D. G. (2009). Methods of systematic reviews and meta-analysis preferred reporting items for systematic reviews and meta-analyses: The PRISMA Statement. J Clin Epidemiol, 62(10), 1006-1012.

Oflaz, F. (2015). Travma yaşamış çocuk ve gençlerin ele alınmasında çocukergen ruh sağlı̆̆1 ve psikiyatri hemşireliği uygulamaları. Turkiye Klinikleri Dergisi, 1(2), 46-51.

Özcan, N. A. ve Arslan, R. (2020). Travma sonrası stres ile travma sonrası büyüme arasındaki ilişkide sosyal desteğin ve maneviyatın aracı rolü. Elektronik Sosyal Bilimler Dergisi, 19(73), 299-314. doi: 10.17755/esosder.548142.

Özcan, N. A. (2019). Yetişkinlerde travma sonrası stres ve öz duyarlılığın travma sonrası büyüme üzerindeki yordayıcı rolü. OPUS Uluslararası Toplum Araştırmaları Dergisi, 14(20), 621-642. doi: 10.26466/opus.594006.

Özçetin, Y. S. Ü. ve Hiçdurmaz, D. (2017). Kanser deneyiminde travma sonrası büyüme ve psikolojik sağlamlık. Psikiyatride Güncel Yaklaşımlar, 9(4), 388-397.

Özen, Y. (2017). Psikolojik travmanın insanlık kadar eski tarihi. The Journal of Social Science, 2(1), 104-117.

Rivas-Diez, R., Sanchez-Lopez, M.D.P. ve Rodrigo-Holgado, I. (2013). 702Posttraumatic stress disorder in battered women by their partners. European Psychiatry, 28(S1), 1-1. https://doi.org/10.1016/S09249338(13)75927-3.

Salsman, J. M., Segerstrom, S. C., Brechting, E. H., Carlson, C. R. ve Andrykowski, M. A. (2009). Posttraumatic growth and PTSD symptomatology among colorectal cancer survivors: a 3-month longitudinal examination of cognitive processing. Psycho-Oncology: 
Journal of the Psychological, Social and Behavioral Dimensions of Cancer, 18(1), 30-41. doi:10.1002/pon.1367.

Schaefer, J. A. ve Moos, R. H. (1992). Life crises and personal growth. In B. N. Carpenter (Ed.), Personal coping: Theory, research, and application (pp. 149-170). Praeger Publishers/Greenwood Publishing Group.

Sharhabani-Arzy, R., Amir, M., Kotler, M. ve Liran, R. (2003). The toll of domestic violence: PTSD among battered women in an Israeli sample.Journal of Interpersonal Violence, 18(11), 1335-1346. doi: $10.1177 / 0886260503256842$.

Solomon, Z. ve Dekel, R. (2007). Posttraumatic stress disorder and posttraumatic growth among Israeli ex-pows. Journal of Traumatic Stress: Official Publication of the International Society for Traumatic Stress Studies, 20(3), 303-312. doi: 10.1002/jts.20216.

Şahne, M. E. (2018). Atatürk Havalimanı saldırısından 6 ay sonra personelde görülen travma sonrası stress belirtileri ve travma sonrası büyüme ile ilişkili faktörler. (Yayımlanmamış Yüksek Lisans Tezi). Üsküdar Üniversitesi, Sosyal Bilimler Enstitüsü, İstanbul.

Şuer, T. (2005). Posttravmatik stres bozukluğu. Medikal Açıdan Stres ve Çareleri Sempozyum Dizisi, 47, 205-210.

Tedeschi, R. G. ve Calhoun, L. G. (2004). Posttraumatic growth: Conceptual foundations and empirical evidence. Psychological Inquiry, 15(1), 1-18. https://doi.org/10.1207/s15327965pli1501 01

Tekcan, E. E. (2018). Yetişkinlerde travma sonrası stres belirtileri ile travma sonrası büyüme arasındaki ilişkide öz-şefkatin düzenleyici rolü. (Yayımlanmamış Yüksek Lisans Tezi). Maltepe Üniversitesi, Sosyal Bilimler Enstitüsü, İstanbul.

Türe, E. ve Barut, Y. (2020). Türkiye'de yapılan oyun terapisi çalışmalarının incelenmesi. Yaşam Becerileri Psikoloji Dergisi,4(8), 127-138. doi: 10.31461/ybpd.837024

Udwin, O., Boyle, S., Yule, W., Bolton, D. ve O'Ryan, D. (2000). Risk factors for long-term psychological effects of a disaster experienced in adolescence: predictors of post traumatic stress disorder. Journal of Child Psychology and Psychiatry, 41(8), 969-979. https://doi.org/10.1111/1469-7610.00685

Yaman, E. N. (2018). The role of event centrality and solidarity in the prediction of posttraumatic stress and posttraumatic growth among the survivors of $10^{\text {th }}$ 
october terrorist attack. (Yayımlanmamış Yüksek Lisans Tezi). Bahçeşehir Üniversitesi, Sosyal Bilimler Enstitüsü, İstanbul.

Yanı, Z. (2018). The mediating effect of rumination in relation to centrality of event, posttraumatic growth and posttraumatic stress disorder among breast cancer survivors. (Yayımlanmamış Yüksek Lisans Tezi). Bahçeşehir Üniversitesi, Sosyal Bilimler Enstitüsü, İstanbul.

Yaşar, M. (2018). Nitel araştırmalarda nitelik sorunu. Muğla Sıtkı Koçman Üniversitesi Ĕ̆itim Fakültesi Dergisi, 5(2), 55-73. doi: 10.21666/muefd.426318.

Yeken, H. (2019). Posttraumatic stress disorder and posttraumatic growth in refugee adolescents: Risks and protective factors. (Yayımlanmamış Yüksek Lisans Tezi). Bolu Abant İzzet Baysal Üniversitesi, Sosyal Bilimler Enstitüsü, Bolu.

Yıldırım, A. ve Şimşek, H. (2016). Sosyal bilimlerde nitel araştırma yöntemleri. Ankara: Seçkin.

Yıldız, Z. S. (2016). Kanser hastalarında travma sonrası stres belirtileri, travma sonrası gelişim ve kendini açma. (Yayımlanmamış Yüksek Lisans Tezi). Maltepe Üniversitesi, Sosyal Bilimler Enstitüsü, İstanbul.

\section{Kaynakça Bilgisi / Citation Information}

Teke, E. ve Avşaroğlu, S. (2021). Türkiye'de travma sonrası stres ve büyüme konusunda gerçekleştirilmiş olan çalışmaların incelenmesi. OPUS- Uluslararası Toplum Araştırmaları Dergisi, 18(43), 6980-7004. DOI: 10.26466/opus.960263. 